\title{
DA DOR NO CORPO À DOR NA ALMA: O CONCEITO DE VIOLÊNCIAS PSICOLÓGICAS DA LEI MARIA DA PENHA
}

\author{
Isadora Vier Machado \\ Universidade Estadual de Maringá \\ Miriam Pillar Grossi \\ Universidade Federal de Santa Catarina
}

\begin{abstract}
Resumo: Este artigo expõe os resultados de pesquisa de campo, realizada entre dezembro de 2010 e julho de 2011 em uma cidade do Sul do Brasil, a respeito da instrumentalização do conceito de violências psicológicas, trazido pela Lei Maria da Penha (Lei 11.340/06), a fim de construir uma leitura da lei a partir deste conceito. Os dados são referentes às/aos agentes que compõem o corpus da polícia, na Delegacia da Mulher e do Ministério Público do município, prioritariamente. Nesses locais, buscou-se compreender como o conceito de violências psicológicas é trabalhado pelas/os agentes e qual o significado teórico-prático que o subjaz. Enfim, coloca-se este dispositivo da lei em posição de questionar a sua própria implementação, de pensar as mudanças que se operam na condição de mulheres em situação de violências e de problematizar as relações entre local e global no campo estudado. A metodologia utilizada foi composta por pesquisa de inspiração etnográfica e levantamento bibliográfico nos campos do Direito, da Psicologia e da Antropologia.

Palavras-chave: violências psicológicas; Lei 11.340/06; agentes de segurança e justiça.
\end{abstract}

\section{Introdução}

Desde a aprovação e vigência da conhecida Lei 1 1.340/2006 (Lei Maria da Penha), temos buscado explicações para a presença do conceito de violências psicológicas no artigo $7^{\circ}$, inciso II, de seu texto legal e, ${ }^{1}$ por meio de fontes teóricas variadas, especialmente

\footnotetext{
Copyright ( 2015 by Revista Estudos Feministas.

${ }^{1}$ Artigo 7, Inciso II: "a violência psicológica, entendida como qualquer conduta que lhe cause dano emocional e diminuição da autoestima ou que lhe prejudique e perturbe o pleno desenvolvimento ou que vise degradar ou controlar suas ações, comportamentos, crenças e decisões, mediante ameaça, constrangimento, humilhação, manipulação, isolamento, vigilância constante, perseguição contumaz, insulto, chantagem, ridicularização, exploração e limitação do direito de ir e vir ou qualquer outro meio que lhe cause prejuízo à saúde psicológica e à autodeterminação" (BRASIL, 2006).
} 
no campo da Antropologia Feminista e dos Estudos de Gênero, esperamos problematizar sua implementação nos níveis de intervenção de segurança e justiça, junto às mulheres brasileiras.

No art. $7^{\circ}$, inc. II, da Lei Maria da Penha, as violências psicológicas são entendidas como todo tipo de conduta que provoca, em termos genéricos, prejuízo à saúde psicológica ou à autodeterminação; e, em termos específicos, dano emocional, diminuição da autoestima, prejuízo ao pleno desenvolvimento, degradação, ou controle. Os meios ou estratégias que podem conduzir a esse dano são arrolados em caráter exemplificativo, misturando claramente condutas que provocam prejuízos no plano moral e no plano efetivamente psicológico, compreendendo as seguintes condutas: ameaça, constrangimento, humilhação, manipulação, isolamento, vigilância constante, perseguição contumaz, insulto, chantagem, ridicularização, exploração e limitação do direito de ir e vir.

Neste texto, escrito a partir de pesquisa de campo realizada entre dezembro de 2010 e julho de 2011 , em uma cidade do Sul do Brasil, apresentamos uma proposta para traçar um panorama socioantropológico das violências psicológicas referidas na Lei Maria da Penha e para, a partir deste, avaliar criticamente o processo de instrumentalização do conceito conforme previsto pela Lei 1 1.340/06. Com isso, demonstraremos como o mesmo é integrado ao cotidiano profissional de membros do Ministério Público e da Delegacia Especializada de Atendimento à Mulher da comarca em que realizamos a pesquisa.

Partimos do princípio que o conceito de violências psicológicas centraliza a historicidade ${ }^{2}$ da Lei Maria da Penha e a concretiza enquanto lugar de memória ${ }^{3}$ dos movimentos feministas brasileiros. Isso porque sinaliza a evolução de uma luta em que a própria noção de violências é estendida, na tentativa de proteger ao máximo os sujeitos de direito - neste caso, as mulheres. No que diz respeito ao conceito de violências psicológicas, portanto, apresenta-se como indicador fundamental dessa transição, já que parece impelir, segundo nossas pesquisas, as/os operadoras/es que lidam com a lei a fundir suas compreensões jurídico-legais e psicossociais, além de representar uma real mudança de contexto local/global sobre a interpretação da dor e das violências.

\section{Metodologia}

O ponto de partida para a construção da análise teórica a que nos propomos tem sido o campo de Estudos de Gênero, referencial teórico essencial para que se avalie o Direito como produtor de tecnologia de gênero. ${ }^{4}$ Além disso, Sandra Harding ${ }^{5}$ destaca que os estudos feministas põem em xeque a racionalidade científica, presente em todas as formas de pensar no Ocidente e, ao mesmo tempo, conseguem incorporar outras reivindicações transversais, de lutas contra outras opressões (coloniais, racistas, homofóbicas, etc.). Seguindo estas autoras, consideramos que os Estudos de Gênero, por permitirem um diálogo cruzado com outras áreas do conhecimento, parecem ser o espaço adequado para que se coloque em questão o modelo cartesiano ${ }^{6}$ e engendrado de ciência que também contamina a produção científica do próprio Direito.

A partir desta base epistemológica, realizamos pesquisa bibliográfica consistente em leituras de campos teóricos variados, especialmente Antropologia, Psicologia, Serviço

\footnotetext{
${ }^{2}$ Anderson Soares GOMES, 2004.

${ }^{3}$ Pierre NORA, 1993.

${ }^{4}$ Teresa DE LAURETIS, 1994, p. 208.

${ }^{5}$ Sandra HARDING, 1996.

${ }^{6}$ Sondra FARGANIS, 1997, p. 224-240.
} 
Social e Direito, buscando as interpretações referentes a violências psicológicas e sobre a implementação da Lei $11.340 / 06$ como um todo.

Pautadas nesses pressupostos, empreendemos uma pesquisa de inspiração etnográfica em que adotamos como marco para desenvolver o procedimento metodológico em campo o trabalho de Cláudia Fonseca, ${ }^{7}$ intitulado Quando tecnologia, lei e família convergem: questões de gênero e geração em conexão com testes de paternidade. Não seria possível escolher um único locus de pesquisa, dada a necessidade de explorar a noção de rede consolidada pelo Pacto Nacional de Enfrentamento à Violência contra a Mulher. ${ }^{8}$

Neste trabalho, apresentamos os dados obtidos junto ao Ministério Público e à delegacia por considerar que, primeiramente, nestes órgãos têm havido uma continuidade no que diz respeito à intervenção nos casos de violências em que se aplica a Lei Maria da Penha. Por não existir, à época, uma vara especializada na comarca pesquisada, os juízes que atendiam os casos de violência doméstica e familiar (terminologia esta, inscrita na Lei 11.340/06) eram aqueles ${ }^{9}$ das Varas Criminais e, eventualmente, de Família, enquanto que, por outro lado, existia uma Promotoria Especializada e também uma Delegacia Especializada de Atendimento à Mulher, esta última, ainda, ativa.

Ou seja, embora a rotatividade de promotores fosse frequente (houve três promotores desde a aprovação da lei), a estrutura destinada ao atendimento das mulheres era fixa, no sentido de centralizar o atendimento das mulheres em situações de violências. O mesmo acontecendo com a delegacia.

Em segundo lugar, embora o campo tenha abrangido níveis de intervenção extrajurídicos, especialmente em um centro de referência, objetivamos problematizar prioritariamente os níveis de segurança e justiça (na figura do Ministério Público), pois são espaços onde foram verificadas tensões reais e evidentes frente ao conceito legal de violências psicológicas.

Na Delegacia da Mulher, acompanhamos as notícias de crimes na própria recepção, assim como alguns registros de Boletins de Ocorrências, quando autorizadas pela investigadora responsável. No Ministério Público, pudemos participar de eventos dirigidos apenas aos membros da instituição (atividades de formação ligadas à Lei 11.340/06), o que se somou aos dias de observação nas salas de espera, especialmente nas horas que antecederam as entrevistas agendadas, e à integração a um grupo de estudos de gênero constituído por membros daquela instituição.

A escolha da localidade levou em conta a rede de contatos que uma de nós vem construindo desde a graduação, passando por estágios em diversas instituições e os conseguintes contatos com advogados/as, estagiários/as, assessores/as, professores/as de Direito e até mesmo promotores/as de justiça, magistrados e delegados/as. Em virtude da garantia de anonimato, não revelamos a identidade das pessoas envolvidas na pesquisa, tampouco o local em que foi realizada. Entretanto, no que diz respeito ao lugar, trata-se de uma cidade com 65 anos; com um pouco mais de 357 mil habitantes, a maior parte jovens, brancos, sendo 185.353 mulheres (entre 0 e 70 anos, habitando as regiões urbana e rural); 230 mil pessoas declaradas de religião católica apostólica romana; com o PIB composto prioritariamente pelo setor de serviços, seguido pela indústria e minimamente pela agropecurária. ${ }^{10}$

7 Claudia FONSECA, 2009

${ }^{8}$ BRASIL, 2010.

๑ O uso do masculino fazia sentido à época, já que não havia juízas atuando nos casos a que fazemos referência.

${ }^{10}$ IBGE, 2010. 


\section{Na porta de entrada do sistema de intervenção: a posição das agentes da Delegacia Especializada}

Em uma das tardes de pesquisa em que estivemos na sala de espera da Delegacia Especializada de Atendimento à Mulher estudada, havia duas mulheres. Uma delas foi chamada a depor e apenas a mulher que a acompanhava ficou na recepção. Esta, por sua vez, contou que era tia da depoente e, fazendo referência ao marido da sobrinha, pôs-se a falar: "ele não é mau, mas sufoca ela". A tia, à vontade para relatar o caso, prosseguiu: "ele tem mania de ciúmes e controle excessivo". Continuou relatando que a sobrinha tem dormido no quarto do filho deles (de sete anos), com a porta trancada e ainda bloqueada pela cama, que ela empurra até o limite da porta. Na cozinha, enquanto ela está no quarto do filho, o homem mexe nas gavetas, abre, fecha, tira facas e faz barulho, como se as estivesse amolando.

De onde estávamos, ouvimos a investigadora explicando para a sobrinha que registraria um Boletim de Ocorrência pelos crimes de ameaça e injúria. Entretanto, havia certo esforço da policial em explicar que, em se tratando de crime de ameaça, a complexidade do procedimento investigativo seria maior, pois não se estava diante de um simples termo circunstanciado (que depois seguiria para o Juizado Especial Criminal), e sim de um inquérito policial que eventualmente seria enviado ao fórum. Parecia uma tentativa da investigadora de confrontar a gravidade do procedimento com a forma de violência ali delatada, aparentemente considerada branda por ela. ${ }^{11}$

Episódios como este não foram tão comuns porque, eventualmente, os casos de violências psicológicas que chegavam ao nosso conhecimento costumavam vir conjugados com outras espécies de violências, especialmente as físicas. ${ }^{12}$

No espaço da delegacia, a pesquisa centralizou-se na atividade de seis policiais, sendo elas: a) a delegada; b) três escrivãs; c) duas investigadoras. Todas com formação universitária, sendo a delegada, uma das escrivãs e uma das investigadoras formadas em Direito e as outras três (uma investigadora e duas escrivãs) formadas, a seu turno, em Letras ou Educação. Aquela que trabalha há mais tempo na delegacia tem 20 anos de serviço na instituição, e aquela que integrou a corporação mais recentemente, justamente a investigadora a quem fazemos referência no relato precedente, o fez há seis meses. No que tange às entrevistas feitas com cada uma, para além da observação in loco, a duração foi de uma hora até uma hora e trinta minutos cada.

Inicialmente, é importante salientar que as cinco policiais estão de acordo a sobre a importância da Lei Maria da Penha para promover uma mudança de contexto na maneira de responder às expectativas das mulheres em situações de violências. Todas, menos a delegada, fizeram fortes críticas à precariedade estrutural da delegacia, precisamente pela falta de pessoal qualificado, de um sistema de dados integrados com o fórum e pela falta de um/a psicólogo/a para responder às necessidades das mulheres.

De acordo com informações da delegada, no primeiro semestre de 2010 , foram registrados 1450 Boletins de Ocorrência. Em outubro daquele mesmo ano, houve 1400 Inquéritos Policiais tramitando na delegacia. Até setembro, foram 280 pedidos de medidas protetivas e 156 Termos Circunstanciados em andamento. Durante o período de observação da delegacia, houve uma informação categórica por parte de todas as pessoas entrevistadas, de que os crimes mais frequentemente noticiados eram de ameaça (art. 147 do Código Penal) e de injúria (art. 140 do Código Penal). ${ }^{13}$

\footnotetext{
${ }^{11}$ Registro n. 23. Observação na Delegacia, no dia 12 de maio de 2011 , das $14 \mathrm{~h}$ e $08 \mathrm{~min}$ às $17 \mathrm{~h}$.

${ }^{12}$ Luciane Lemos da SILVA, Elza Berger Salema COELHO e Sandra Noemi Cucurullo de CAPONI, 2007.

${ }^{13}$ BRASIL, 2002.
}

564 Estudos Feministas, Florianópolis, 23(2): 561-576, maio-agosto/2015 
Todas as policiais estão, portanto, expressamente de acordo com a existência de um fenômeno de violência psicológica, diante de casos corriqueiros em que as mulheres relatam toda sorte de humilhação, perseguição, ameaça, xingamento, etc. Segundo elas, várias mulheres chegam à delegacia para procurar um tipo de ajuda que não faz parte dos serviços disponíveis. Certamente, essas dificuldades são constituídas a partir da exposição da delegacia e de sua representação no imaginário popular enquanto porta de entrada para a resolução de conflitos quotidianos. ${ }^{14} \mathrm{Com}$ isso, outras instâncias da rede, como, por exemplo, os Centros de Referência são comumente acessados somente depois de encaminhamentos feitos na delegacia, o que aumenta consideravelmente a carga de trabalho das policiais.

As agentes descreveram o sofrimento psicológico das mulheres como algo evidente, mas que, para elas mesmas, é imperceptível na maior parte do tempo. A literatura dedicada à temática das violências psicológicas ${ }^{15}$ esclarece que essa sutileza faz parte das técnicas de controle e terrorismo psicológico que se instauram em prejuízo da pessoa que sofre a violência. Como a prática é sutil e repetitiva, estabelece-se um estado de confusão mental em que o ofensor procura meios de fazer com que sua vontade predomine. Quando chegam à delegacia, significa que houve um turning point na percepção das mulheres e que, de algum modo, pela dor, pela difusão da Lei Maria da Penha, ou mesmo pelo apoio de terceiros (como o caso da tia que conduziu a sobrinha à delegacia), resolveram buscar intervenção. No período pesquisado, uma das escrivãs retratou o cenário de denúncias nesse momento inicial, indicando a configuração das violências psicológicas no espaço da delegacia:

Você xingar alguém de burra, você está inferiorizando ela. Você xingar ela de feia, 'sua gorda', isso, você vai destruir [...] a autoestima dela acaba. Você acaba com a pessoa. Então, muitas são 'você é burra, você não é capaz de nada, você é simplesmente uma dona de casa'. A gente ouve todo tipo de coisa aqui! Falando mal, até, sabe... deteriorando até o órgão sexual dela. Entendeu? Eu não sei pra você, mas uma vagina, ela é uma vagina pra todo mundo! Entendeu? Agora, você ficar, 'você é feia, você é gorda, você é burra, você é incapaz, você é não sei o que, você...'. [...] Isso é uma violência psicológica. É o homem querer comandar, querer mandar, querer fazer e desfazer, 'você vai deixar, você não vai, se eu não deixar'. E é assim.

Para outra policial, muitas mulheres vão à delegacia para aliviar sua dor. Depois disso, prosseguir com uma demanda judicial não faz mais sentido. Esta mesma investigadora revelou que não é raro ouvir das mulheres "Ah, mas vocês não vão chamar pra conversar?". Entretanto, é justamente quando as mulheres decidem que querem prosseguir com um registro formal da ocorrência que a crítica ao conceito de violências psicológicas aparece. A delegada se manifesta:

É, na verdade ela trouxe o conceito, mas não definiu os crimes, né? Então, gera uma série de discussões isso. Muitas vezes, também, as pessoas não entendem isso, que ela não tipificou esse conceito, que ela definiu. Então, a gente às vezes tem um problema [sobre] aquilo que a gente discutiu: 'ah, mas a violência psicológica não é punida, né?'. É... se tá tipificada, é. Se não estiver tipificada, não, né? Então, assim, nesse ponto, eu acho que teria que ter uma reforma pra abranger quais são as condutas que se enquadram, e alterar o tipo penal, né? Em violência psicológica, ou em violência patrimonial, ou...

${ }^{14}$ Guita Grin DEBERT, Maria Filomena GREGORI e Adriana PISCITELLI, 2006, p. 13-56.

${ }^{15}$ Marie-France HIRIGOYEN, 2006; Isabelle LEVERT, 2011; Mary Susan MILLER, 1999; Lyse MONTMINY, 2005; Adelma PIMENTEL, 2011. 
O tipo penal é uma construção jurídica que dita a atividade das/os profissionais da carreira. Conforme pontua Maria Filomena Gregori, ${ }^{16}$ toda a complexidade e a dinâmica das relações conjugais deve se resumir à máxima da legalidade e encontrar na tipicidade suas amarras e limites possíveis. O desafio das agentes policiais é o de promover uma correspondência satisfatória entre o mundo dos fatos e os enunciados da lei. No caso relatado, a saída encontrada foi o registro da ocorrência pelo crime de ameaça (art. 147 do Código Penal), mesmo assim, a investigadora não deixou de chamar a atenção da mulher para a gravidade do procedimento para o homem, na tentativa de se certificar de que a mulher não desistiria da ação penal novamente.

Outra crítica feita pela autoridade policial, nesse mesmo sentido, diz respeito à fluidez do conceito e à dinâmica de mudança de comportamento que pode ser eventualmente considerado violento em uma determinada época, porém não em outra. Inconsistências conceituais que estão também presentes nas discussões mais generalizadas a respeito das violências. Os riscos apresentados pela expansão do campo semântico da violência são constantemente assinalados. ${ }^{17}$ Não deixa de ser diferente com os casos de violências psicológicas.

De todo modo, na delegacia, a maioria das policiais reconheceram a importância do conceito previsto pela lei e admitiram trabalhar com situações de violências psicológicas. A instrumentalização do conceito passa por tentativas de enquadramento legal (sobretudo por meio dos tipos penais de ameaça e injúria), caso a vontade manifesta das mulheres seja de prosseguir com o indiciamento dos autores e eventual processo criminal. Este enquadramento, entretanto, reduz a complexidade dos casos às estratégias pontuadas pela Lei Maria da Penha e não é feito sem que se ressaltem as consequências jurídicas ao algoz, em um claro questionamento sobre a proporcionalidade da conduta e da resposta auferida. Por outro lado, se a vontade não é propriamente a de dar sequência à penalização do caso, a prática local é de encaminhar aos serviços de ajuda social/psicológica, sobretudo no centro de referência local, já que a psicóloga da delegacia atende apenas crianças e adolescentes. As principais críticas ao conceito foram, enfim, tecidas pela própria delegada, profissional de carreira jurídica, referindo-se às dificuldades de enquadramento legal e àquelas relacionadas à maleabilidade do conceito.

\section{No Ministério Público: o confronto entre as violências psicológicas e a letra da lei}

O caso daquele dia era o de uma ex-mulher e de um ex-marido, casados durante 34 anos, atualmente separados, porém vivendo na mesma casa. Por conta da obrigação de dividir o mesmo espaço, a mulher alegava sofrer constantes episódios de violência psicológica, tendo dito que "se ele agride verbalmente, dói às vezes mais do que se agride fisicamente". Explicou que, além de ter que viver como uma refém em sua própria casa (dormindo no quarto do filho, comendo em horários diversos do ex-marido, assistindo a tevê em outro lugar que o de costume, etc.), também há o fato de o ex-marido ter se envolvido com um rapaz mais novo, que ele leva para dormir com ele no quarto que um dia foi do casal.

A postura do Ministério Público frente aos casos de violências psicológicas é primordial porque, a depender da posição adotada pelo/a promotor/a de justiça, os fluxos de violências psicológicas podem ser barrados já na porta de entrada do sistema de

${ }^{16}$ DEBERT, GREGORI e PISCITELLI, 2006, p. 67-86.

17 Theóphilos RIFIOTIS, 1999.

566 Estudos Feministas, Florianópolis, 23(2): 561-576, maio-agosto/2015 
justiça, uma vez que o órgão titular das ações penais é, justamente, o órgão ministerial, nos termos do art. 129, inciso I, da Constituição federal: "São funções institucionais do Ministério Público: I - promover, privativamente, a ação penal pública, na forma da lei". ${ }^{18} \mathrm{O}$ caso em questão naquele dia era uma representação das situações de violências psicológicas já judicializadas. Certamente, a instância judicial havia legitimado o enquadramento legal da conduta, feito outrora na delegacia, para chegar até o ponto de marcar a audiência as alternativas, a partir de então, seriam jurídicas. A não ser que iniciativas voluntárias, como o atendimento pela psicóloga, motivado por um dos promotores de justiça, tivessem lugar.

Portanto, os autos de inquérito formulados na delegacia são enviados a juízo para que o Ministério Público, responsável pelo oferecimento da denúncia, possa avaliar a viabilidade para prosseguir o feito. Essa instituição, como bem se sabe, é integrada por profissionais de alta formação jurídica.

A pesquisa foi feita com representantes da promotoria tecnicamente qualificados, dos quais três são mestres em Direito, sendo que um deles iniciava seus estudos doutorais em uma universidade pública local. Dos três mestres, um tem formação específica na área da Criminologia. Tivemos contato, portanto, com quatro promotores, três homens e uma mulher. Dois homens estavam alocados em promotorias criminais (porém já trabalharam na promotoria especializada na Lei Maria da Penha); um homem ocupava o posto da promotoria especializada; e a mulher era promotora do Juizado Especial Criminal da comarca, tendo lidado, então, por muitos anos, com processos de violência doméstica e intrafamiliar sob a vigência da Lei 9.099/95, sobre os Juizados Especiais Cíveis e Criminais. Nessa comarca, a média etária dos/as promotores/as é menor do que a dos/as juízes/as e está compreendida em uma faixa entre 40 a 50 anos, quando já alcançam o posto de titulares, deixando de ser substitutos/as.

O promotor que trabalhava exclusivamente com a Lei Maria da Penha é conhecido por um perfil combativo e destoante dos demais membros da classe, desloca-se pela cidade de bicicleta, não se veste de maneira formal (costuma trajar jeans e camisa de manga curta, raramente o vi de terno e gravata), deixa a porta do gabinete aberta para que o público circule livremente enquanto ele trabalha. É ele quem recebia os inquéritos da delegacia e avaliava se havia possibilidade de oferecer a denúncia. Iniciada a ação penal, os outros promotores das varas criminais davam sequência ao feito. Logo, o promotor que, em um primeiro momento, recebia uma mulher em situação de violências, não era o mesmo presente na fase instrutória do processo, que é quando acontecem as oitivas e demais produções de provas. ${ }^{19}$

Contrariamente ao que acontece na delegacia, os casos que chegam ao fórum já estão reduzidos aos termos da lei penal, por conta do encaminhamento dos autos de inquérito policial ou dos expedientes de medida protetiva vindos, já documentados, da delegacia. Quanto às estatísticas, por sua vez, não há uma sistematização oficial dos casos, por isso, a seccional da Ordem dos Advogados do Brasil ${ }^{20}$ fez um levantamento, em 2012, para constituir o relatório que foi encaminhado à CPMI da Violência contra a Mulher naquele mesmo ano. Por meio desta consulta, 569 advogados e advogadas foram sondados/as a respeito de sua atuação em casos de violência contra a mulher, tendo sido verificada a incidência prioritária de violência física $(31,98 \%)$, seguida de violência

${ }^{18}$ BRASIL, 1988

${ }^{19}$ Esse entrave só foi vencido com a implementação (anunciada pelo Tribunal de Justiça do Estado no início de 2012, porém, efetivada apenas em 2013) da vara especializada.

${ }^{20} \mathrm{OAB} / \mathrm{PR}, 2012$. 
psicológica $(29,5 \%)$ e moral $(20,93 \%)$. Levantamento numérico que corresponde às informações repassadas pelas promotorias.

Diante dessa realidade, a posição dos promotores e da promotora foi demarcada pela intervenção criminalizante, o que influenciou as respectivas posturas com relação à própria Lei Maria da Penha. Esta, por sua vez, não foi uniforme. Três identificaram a lei como importante instrumento para promover igualdade entre homens e mulheres e para dar visibilidade à luta das mulheres contra as violências. Um dos homens, atuante em uma promotoria criminal e com formação criminológica, marcou sua postura contrária à influência do Estado na vida das pessoas, em especial, nas "questões familiares", embora tenha admitido o benefício social desse instrumento normativo, consistente em uma possível mudança futura do comportamento dos homens, seja por pressão social, seja pela sanção penal.

No que tange ao conceito de violências psicológicas, a postura desses agentes ${ }^{21}$ esteve também ligada à sua posição frente a uma lei que oferece um conceito de violência. O mesmo promotor de justiça que criticou a intervenção estatal na família defendeu que o ideal é que os conceitos abstratos sejam formulados pela prática dos tribunais, por meio da jurisprudência, e não por dispositivos de lei. De um modo ou de outro, nenhum deles pontuou grandes inconvenientes no fato de haver uma previsão legal do conceito de violências psicológicas, porque, lembraram todos, o conceito foi posto em lei para permitir que se pense no maior número de condutas possíveis, no momento de judicializar ${ }^{22}$ um comportamento. Para esse tipo de comportamento, definido claramente pelos promotores de justiça que ocupam os postos das varas criminais como condutas de menor importância na maior parte dos casos (especialmente, quando fizeram comparações claras com delitos contra a vida ou contra a integridade física), é preciso otimizar e utilizar os crimes e contravenções penais já previstos em lei.

O princípio da legalidade constitui a base de trabalho de todos os promotores criminais. ${ }^{23}$ Por conta disso, os argumentos levantados com respeito ao conceito de violências psicológicas faziam referência à necessidade irrenunciável de se encontrar um correspondente no Código Penal, muito mais do que foi apontado na delegacia. A resposta de um dos promotores de justiça à pergunta "O que o senhor compreende por violências psicológicas?" ilustra bem essa restrição:

É, eu não tenho um conceito...assim... definido a respeito disso. Como a atuação é mais na área criminal, [...] os casos de violência psicológica, para efeitos criminais, são os delitos que resultam de violência psicológica. Como por exemplo, ameaça. Ameaça não deixa de ser uma grande ameaça psicológica, porque a vítima se sente tolhida na sua liberdade, no seu direito de paz e tranquilidade onde ela estiver. Então, [...] resulta nesse tipo de delito. Então, a visão que eu tenho é mais voltada ao aspecto criminal. Embora a Lei Maria da Penha fale que todos os tipos de violência contra a mulher constituem violência doméstica e familiar contra a mulher, a violência psicológica, a violência física, etc., para efeitos criminais, são os conceitos, de delitos, são os do Código Penal, como não poderia deixar de ser. E acho que não há nenhum prejuízo em a lei ter dito isso. Então os tipos penais estão aí, no Código Penal, com algumas modificações pontuais, mas a Lei Maria da Penha não criou nenhum crime, nenhum delito. Ela conceitua esses tipos de violência, mas que, na área criminal, são os delitos existentes no Código Penal que se encaixem nesses tipos de violência.

${ }^{21}$ As autoras utilizam a declinação de gênero de modo a destacar o uso do feminino; entretanto, em algumas situações, exclusivamente, houve a impossibilidade de fazê-lo sem que isso comprometesse a compreensão do conteúdo, razão pela qual dispõem do uso do plural no masculino.

22 RIFIOTIS, 2007, p. 238

${ }^{23}$ Welliton CAIXETA MACIEL, 2010.

568 Estudos Feministas, Florianópolis, 23(2): 561-576, maio-agosto/2015 
A visão, nessa instância, é visivelmente mais fechada a possibilidades extralegais do que a das policiais, embora o promotor encarregado especificamente dos processos ligados à Lei 11 .30/06 resuma a opinião dos membros da classe, admitindo o papel político da lei e ressaltando restrições e cuidados a serem tomados no momento de sua aplicação:

\begin{abstract}
Até por uma questão de garantismo, o ordenamento penal tem que ser alterado mais conservadoramente, com outros tipos, como Maria da Penha. [...] Mas Existe o Estatuto da Mulher vítima de violência doméstica, um nome horrível, por isso está como Maria da Penha, mas ele é, de fato, um estatuto, porque estabelece princípios, garantias, conceitos, também nessa linha, dos direitos coletivos, difusos, ou de grupos, né. Então acho que é natural o que aconteceu, e foi um fenômeno jurídico-político, a lei de proteção à mulher vítima de violência fazer referência a formas de violências que ainda não foram tipificadas, e que podem ser tipificadas. Daí a gente tem que pensar, de novo, no Congresso Nacional né? Na lei que ele faz. Esse Congresso é homem, 'macho'. Por que fez uma Lei Maria da Penha? Isso quer dizer que o Congresso é só representativo mesmo, formal. Só que é mais difícil você ter um movimento pra, e é mais perigoso também, você ter um movimento pra alterar uma lei penal. Mas eu acho que é um caminho. Então, quando eu identificar a violência psicológica, ainda não tenho o tipo de violência psicológica, o tipo vai ter que ser analisado com todos os cuidados que o Direito Penal merece, sob pena de que se crie um Estado de Exceção.
\end{abstract}

Portanto, houve reconhecimento explícito da função estratégica do conceito, de natureza jurídico-política, embora sua instrumentalização passe pela necessidade de enquadramento legal.

Enfim, embora a prática de encaminhamentos a serviços de natureza psicossocial não seja tão comum quanto na delegacia, conforme se percebe pelo próprio caso relatado no início deste item, os promotores e a promotora mostraram uma consciência incontornável sobre a importância do trabalho psicossocial, adquirida com a prática profissional, motivando, inclusive, projetos voluntários no espaço do fórum (um deles, o da psicóloga que conduziu a sessão pré-audiência em questão; e o outro, posto em prática pela promotora do Juizado Especial Criminal, mas já extinto), ou destacando sua relevância nos espaços extrajurídicos. Os quatro, inclusive, resgataram a necessidade de um tribunal especializado nos mesmos termos da Lei $11.340 / 06$, porque os projetos voluntários são temporários e não absorvem a demanda necessária ${ }^{24}$ Quer dizer, o discurso jurídico restringe a instrumentalização do conceito, mas a formação individual, a sensibilidade, as crenças e outros aspectos subjetivos os levam, no limite das possibilidades, a buscar alternativas que, em boa parte do tempo, acontecem dentro do sistema de justiça.

\title{
4 Notas conclusivas: uma leitura da Lei Maria da Penha a partir das violências psicológicas
}

Ao eleger um conceito legal para ser objeto de análise - a violência psicológica foi possível obter um registro preciso de diálogo com as/os nossas/os interlocutoras/es em campo. Dado que, no limite das possibilidades teóricas, as noções de trauma psíquico, de trauma, de traumatismo, de dor, de violência simbólica ou de sofrimento psicológico, por exemplo, podem ser encontradas em diversas leituras.

Foi no campo da Psicanálise, certamente, que se consolidou um dos aportes mais difundidos a respeito do tema, com o conceito de trauma psíquico, desenvolvido por Freud

${ }^{24}$ Em nível estadual, já existe inclusive um grupo de estudos dentro do Ministério Público, dedicado às questões de gênero e sexualidades. 
ao final do século XIX, quando se estava, ainda, no início da formulação de sua teoria psicanalítica. ${ }^{25}$ No domínio da Sociologia, é igualmente importante reter o conceito de violência simbólica, estruturado por Pierre Bourdieu e Jean-Claude Passeron, ${ }^{26}$ pois se trata de fenômeno que em muito se aproxima da definição legal das violências psicológicas. $O$ poder da violência simbólica é definido como "todo poder que chega a impor significações e impôlas como legítimas, dissimulando as relações de força que estão na base de sua força, acrescenta sua própria força, isto é, propriamente simbólica, a essas relações de força". ${ }^{27}$

Neste trabalho, não deixamos de tomar tais aportes como importante substância para compreender e problematizar o conceito legal. Entretanto, com isso, não pretendemos nos esquivar do nosso objeto de análise. De acordo com Catherine Ballé, ${ }^{28}$ "as categorias jurídicas são então um ponto de partida indispensável mesmo se não dão conta na totalidade da complexidade das condutas sociais".

Em particular, no caso das violências psicológicas, há uma evidente complexidade conceitual que motivou a busca das vias pelas quais têm sido instrumentalizadas. Ao compreender como o conceito é vivenciado e operacionalizado, abre-se uma via para comprovar que a discussão teórica a respeito do mesmo é fundamental no processo de implementação da Lei Maria da Penha. Primeiramente, por dar meios para aperfeiçoar as estratégias extrajurídicas que o diploma legal esboça. Em segundo lugar, porque resume muitos elementos da história da Lei Maria da Penha que atribuem sentido às escolhas feitas pelas instâncias envolvidas em sua elaboração.

Diante da apresentação de duas diferentes perspectivas de instrumentalização do conceito de violências psicológicas, é possível notar que este elemento, por si só, não modificou amplamente as práticas das/os agentes de segurança e justiça, já que a lei penal segue sendo a base tipológica que motiva a atuação dessas/es profissionais. Embora haja uma aceitação mais ampla do conceito no nível da delegacia especializada, entende-se que isso se deve ao fato de essa instituição representar a porta de entrada do sistema de intervenção, tendo ampliado consideravelmente a própria compreensão de comportamentos violentos. Portanto, são mais conhecidas, mais procuradas pelas mulheres e assumem o compromisso de promover atendimentos, registros de Boletins de Ocorrência, investigações e encaminhamentos a outras instâncias. Na promotoria, as/os profissionais lidam com conflitos e episódios de violências já reduzidos ao patamar legal, fazem uma leitura do conceito de violências psicológicas como situações de menor gravidade, lembrando sempre que seu dever é pensar as violências em um nível criminal, embora todos/as tenham se mostrado de acordo sobre a importância de um sistema de intervenção psicossocial mais bem instrumentalizado, ainda que dentro da esfera judicial.

Mesmo tendo chegado à constatação de que o conceito do art. $7^{\circ}$, inc. II, da Lei Maria da Penha não modificou profundamente a prática de intervenção, acreditamos ser fundamental partir da análise de sua instrumentalização para avaliar seu significado subjacente. Ao impelir os/as agentes a ver a lei para além de sua perspectiva criminalizante, catalisa uma condição socioantropológica, retrata a historicidade dos movimentos feministas brasileiros e consolida uma nova maneira de conceber as mulheres nas relações conjugais que, aos poucos, pode ser capaz de modificar a postura desses/as agentes participantes da pesquisa.

Sendo assim, primeiramente, a disposição desse conceito no texto legal vem para firmar uma nova visão, a que chamamos de "visão tripartida" da Lei Maria da Penha:

\footnotetext{
${ }^{25}$ Sigmund FREUD, 2003, p. 107.

26 Pierre BOURDIEU e Jean-Claude PASSERON, 1982

${ }^{27}$ BOURDIEU e PASSERON, 1982, p. 19.

${ }^{28}$ Catherine BALLÉ, 1976, p. 24, tradução nossa.
} 
composta por suas dimensões normativo-penal, protetiva e nominativa. Esse caráter já tem sido identificado e, aos poucos, incorporado no discurso de determinados/as agentes da rede de intervenção. Porque, ao mesmo tempo em que a lei alinha a intervenção frente aos casos de violências a uma perspectiva criminalizante, nas três etapas da atuação das/os agentes operadoras/es do Direito (policial, judicial ou já na fase de execução da pena), também lança mão de instrumentos de proteção e de uma perspectiva nominativa. Há dispositivos em que se destaca a dimensão protetiva, como aqueles contidos no Capítulo II, que enuncia as medidas protetivas de urgência. Por sua vez, a dimensão nominativa é marcadora evidente da complexa luta política que resultou na aprovação da Lei Maria da Penha. Neste nível interpretativo, presente no discurso dos/as agentes pesquisados/as, é possível perceber, por exemplo, quais compreensões de violências, feminismos, ou mulheres foram inscritas no texto normativo.

É justamente neste último nível que se coloca o conceito de violências psicológicas por meio do qual se nota uma atribuição de sentido diverso ao corpo das mulheres. Se, até então, o poder que se inscrevia sobre estes corpos as colocava, por exemplo, no lugar de histéricas ou anoréxicas, ${ }^{29}$ a Lei $11.340 / 06$ subverte a inscrição opressora da feminilidade sobre os corpos das mulheres, concebendo-os agora como uma entidade psicofísica e aumentando as possibilidades de expressão dessas mulheres e de resguardo de sua integridade. Nessa perspectiva, Carmen Hein de Campos $^{30}$ lembra-nos que há, na Lei Maria da Penha, um lugar de fala das mulheres:

Ao construir uma legislação específica para nortear o tratamento legal da violência doméstica, o feminismo disputa um lugar de fala até então não reconhecido pelos juristas tradicionais. É que a afirmação dos direitos das mulheres, através de uma legislação específica, ameaça a ordem de gênero do direito penal afirmada por esses juristas. Dito de outra forma, os pressupostos teóricos sob os quais têm se sustentado a formulação sexista sobre o que deve ou não ser considerado um tema de relevância jurídica.

Em que pese a crítica feita ao rigor da esfera criminalizante da chamada Lei Maria da Penha, a mesma autora, junto do criminólogo Salo de Carvalho, ${ }^{31}$ reforça que, na realidade, este instrumento normativo inaugurou um novo modelo que ultrapassa o campo unicamente repressivo, e a sinalização da modalidade de violências psicológicas sintetiza, justamente, essa nova realidade. O problema que se impõe aos/às agentes que atuam nos níveis de segurança e justiça é que essas pessoas são colocadas em posição de rever sua crítica jurídica feita à Lei Maria da Penha, dando-se conta de que se trata de uma crítica autocentrada, focada em uma leitura da lei que se resume à sua dimensão normativopenal, enquanto que, na verdade, ela deveria se estender às outras dimensões do texto, por uma compreensão da violência que não seja exclusivamente jurídica. Quando são questionadas/os sobre aspectos ligados ao conceito de violências psicológicas, parecem mais abertas/os a essa reflexão.

Em segundo lugar, o conceito de violências psicológicas é fundamental porque, além de demarcar uma nova postura frente às violências contra mulheres, comprova a vinculação entre estratégias locais e estratégias globais na luta contra o fenômeno. Dado que, muito provavelmente, não haveria tal conceito em lei, não fossem as evoluções produzidas a partir de normativas e documentos internacionais. Afinal, como bem relembraram os promotores de justiça, a própria Lei Maria da Penha, na íntegra, apresentase como estatuto político complexo, inserida em um contexto histórico de luta dos movimentos

29 Susan R. BORDO, 1997.

${ }^{30}$ Carmen Hein de CAMPOS, 2011 , p. 7

${ }^{31}$ CAMPOS e Salo de CARVALHO, 2011. 
feministas brasileiros, favorecido igualmente pelas recomendações da OEA ${ }^{32}$ No que tange especificamente às violências psicológicas, representam um significativo resgate da Convenção Interamericana para Prevenir, Punir e Erradicar a Violência contra a Mulher (Convenção de Belém do Pará), que pioneiramente atribui às mulheres o direito a que se respeite sua integridade física, psíquica e moral (art. $4^{\circ}$ ) e do chamado Modelo de leyes y políticas sobre violencia intrafamiliar contra las mujeres, ${ }^{33}$ documento internacional que propõe um conceito de violências psicológicas muito próximo ao da Lei Maria da Penha. $O$ processo de reconhecimento explícito de uma modalidade de violências psicológicas só tende a evidenciar a ligação da perspectiva local com a global e impele as pessoas que operam a lei em seu quotidiano profissional a pensar as violências contra mulheres dentro de um quadro territorial macro de direitos humanos.

Em terceiro lugar, nota-se que a inserção do conceito de violências psicológicas em lei denota uma nova visão das próprias mulheres, enquanto sujeitos de direitos e não mais como membros de uma família, ${ }^{34}$ aspecto este que é reforçado por outros dispositivos, tal qual o parágrafo único do art. 5, que pontua a aplicabilidade da Lei 11.340/06, independentemente da orientação sexual das mulheres envolvidas no contexto violento. Esta perspectiva foi mais precariamente admitida pelos dois promotores criminais, tendo um deles, aliás, feito referência à problemática interferência do Estado nas "famílias".

Mesmo assim, outra consideração importante a respeito do conceito é que ele revela que a implementação da Lei Maria da Penha é uma tarefa permeada pelas subjetividades, crenças e formação específica das/os agentes de segurança e justiça em questão. É também um signo das mudanças operadas nos papéis de gênero, em que não se colocam mais as mulheres em posição de suportar essa forma de opressão. Conjuntamente, a previsão legal dessa tipologia de violência põe em xeque a maneira de lidar com o conceito na delegacia e na promotoria, especificamente em virtude de dificuldades probatórias, mas também, e acima de tudo, pelo distanciamento que as/os profissionais têm das questões de gênero. Há uma trama de facilidades e dificuldades em adequar o conceito à realidade de intervenção, que é determinada por aspectos subjetivos, em cada instância.

Em último lugar, gostaríamos de salientar como o conceito de violências psicológicas foi um importante parâmetro a partir do qual pudemos destacar a compreensão que as/os entrevistadas/os tinham das próprias relações de gênero. No descompasso entre essa compreensão e a extensão conceitual da Lei Maria da Penha, que hoje concebe formas de violências antes não pontuadas em nível legal, aspectos subjetivos das/os profissionais são determinantes para o acolhimento das mulheres em situações de violências.

Uma vez que a Lei Maria da Penha relaciona as violências domésticas e intrafamiliares com a dimensão dos gêneros, ${ }^{35}$ consideramos importante, na inserção em campo, também perguntar às pessoas participantes o que significariam "relações de gênero". As respostas traduziram, dentre outros elementos, que enquanto os/as agentes não flexibilizam o cânone jurídico para se colocar em contato com outras compreensões de mundo, as dificuldades quotidianas de se enfrentar uma tipologia de violências que ainda não foi capturada pelas leis penais são resolvidas por estratégias provisórias e dependem sempre da postura individual destes/as.

Na delegacia, as policiais não se dispuseram a sugerir um conceito, sendo que a fala de uma das escrivãs foi emblemática:

${ }^{32}$ CLADEM, 2011; Adriana ESTIGARA, 2007.

${ }^{33}$ OPS, 2004

${ }^{34}$ Mathias COUTURIER, 2011.

${ }^{35}$ Joan SCOT, 1995. 
Isso ainda confunde muito a cabeça da gente, né. Eu acho que não teve uma... como é que eu vou te dizer... acho que, pra todo mundo que trabalha na Delegacia da Mulher, tinha que ter uma... uma palestra pra essa determinação de gênero. Eu fiquei um pouco perdida nessa situação de gênero, não vou mentir pra você. Não... não vou conseguir te explicar. Eu sei pra mim, mas não sei te explicar. Porque eu aprendi mal. E quando a gente aprende bem, a gente sabe explicar bem. Mas eu não sei desenvolver o assunto pra você. Então, nem adianta tentar. ${ }^{36}$

Na fala da delegada, a única agente disposta a arriscar um conceito, é evidente a confusão que se produz entre categorias como gênero e orientação sexual, informando que o conceito de gênero remete à vulnerabilidade ligada aos papéis sociais que são atribuídos a homens e mulheres, que não são relativos, apenas, aos heterossexuais, mas às pessoas das mais diversas orientações sexuais. ${ }^{37}$

À exceção do promotor de justiça que opera a Lei Maria da Penha, as pessoas não foram capazes de balizar claramente a diferença entre gênero e sexo. A resposta de um dos promotores de justiça das varas criminais exemplifica essa dificuldade, também no Ministério Público, mesmo tendo sido ele o responsável por implementar o serviço de atendimento psicológico que antecede às audiências de uma das varas criminais:

Olha... assim, no âmbito de aplicação [da Lei Maria da Penha], é o gênero mulher. Sexo feminino. Teve entendimentos, no início, de que a Lei Maria da Penha estaria acobertando, né... estaria protegendo alguns homens em situação de violência doméstica, também, né... porque acontecem casos, esporádicos, mas acontecem. ${ }^{38}$

Para Anne Fausto-Sterling, ${ }^{39}$ escolher o sexo como critério padrão e enganosamente imutável, é, por si só, uma opção social. Com base nisso, esta autora defende que "o modo como tradicionalmente concebemos a identidade sexual e de gênero estreita as possibilidades da vida ao mesmo tempo em que perpetua a desigualdade de gênero. Para mudar a política do corpo, precisamos mudar a própria política da ciência". Ciente de que a capacitação profissional é um dos eixos, tanto da Política Nacional, quanto do Pacto Nacional de Enfrentamento à Violência Contra Mulheres, e de que a Lei Maria da Penha data de 2006, fui surpreendida por respostas como:

Gênero... Explique melhor. Não consegui entender a sua pergunta. (Promotor de Justiça)

E... você perguntou de questões de gênero, né? Aí eu não saberia te dizer. Talvez eu não tenha entendido a pergunta.

(Escrivã da Delegacia da Mulher)

Não, nunca ouvi falar, não sei nem o que que é isso! (Investigadora da Delegacia da Mulher)

Nessa linha, Miriam Pillar Grossi ${ }^{40}$ ressalta que a teoria feminista empenha-se em distinguir identidade de gênero de sexualidade, porque o conceito de gênero ainda vem muito fortemente associado ao de sexualidade, no Ocidente. A dificuldade advém do fato de que "Além de diferentes formas de interpretar a situação das mulheres em nossa cultura, categorias como 'sexo e gênero, identidade de gênero e sexualidade' são tomadas muito seguidamente no Brasil como equivalentes entre si".

${ }^{36}$ Registro 11. Entrevista com escrivã de polícia, em 8 de junho de 2011.

${ }^{37}$ Registro 09. Entrevista com a delegada da DEAM, em 27 de maio de 2011.

${ }^{38}$ Registro 02. Entrevista com promotor de justiça, em 2 de fevereiro de 2011.

${ }^{39}$ Anne FAUSTO-STERLING, 2001, p. 27

${ }^{40}$ Miriam Pillar GROSSI, 1998, p. 12. 
Cabe como exemplo a figura do promotor especializado, que, em sua prática profissional, quando perguntado sobre a possibilidade de responder aos casos de violências psicológicas, afirmou que uma das saídas que tem encontrado é utilizar um tipo penal que chamou de "guarda-chuva", que é o constrangimento ilegal, ${ }^{41}$ porque, em suma, entende que o mais importante é resolver o problema das mulheres pelas vias possíveis. ${ }^{42}$

Portanto, na verdade, o conceito de violências psicológicas sintetiza justamente a maneira com que a Lei Maria da Penha tem sido implementada ao longo de seus seis anos de vigência: a depender da subjetividade, da disposição e das concepções dos/as agentes, dispostas/os - ou não - a buscar uma solução para o problema que se apresenta. Sensibilidade, circunstância, ou boa vontade - no final das contas, ainda são os elementos definitivos para que se possa conceber uma mudança de paradigmas em que não se recrimine apenas a dor no corpo, como também a dor na alma.

\section{Referências}

BALLÉ, Catherine. La menace: un langage de violence. Centre National de la Recherche Scientifique: Paris, 1976.

BORDO, Susan R. "O corpo e a reprodução da feminidade: uma apropriação feminista de Foucault”. In: JAGGAR, Alison M.; BORDO, Susan R. Gênero, corpo, conhecimento. Tradução de Britta Lemos de Freitas. Rio de Janeiro: Rosa dos Tempos, 1997. p. 19-41.

BOURDIEU, Pierre; PASSERON, Jean-Claude. A reprodução: elementos para uma teoria do sistema de ensino. Rio de Janeiro: Ed. Francisco Alves, 1982.

BRASIL. Lei n. 10.406, de 10 de janeiro de 2002: institui o Novo Código Civil Brasileiro. 2002. Disponível em: http://www.planalto.gov.br/ccivil_03/leis/2002/I10406.htm. Acesso em: 10 mar. 2012.

BRASIL. Presidência da República. Lei n. 11.340, de 7 de agosto de 2006. (Lei Maria da Penha). Cria mecanismos para coibir a violência doméstica e familiar contra a mulher... Disponível em: http://www.planalto.gov.br/ccivil_03/_ato2004-2006/2006/lei/l1 1340.htm. Acesso em: 9 jul. 2012.

Secretaria Especial de Políticas para Mulheres-SPM. Política Nacional de Enfrentamento à Violência contra as Mulheres. Brasília, 2010. Disponível em: http:// www.spm.gov.br/sobre/publicacoes/publicacoes/2010/PactoNacional_livro.pdf. Acesso em: 21 abr. 2012.

CAIXETA MACIEL, Welliton. "Processos institucionais de administração de conflitos, produção de 'verdades jurídicas' e representações sociais sobre a questão da violência doméstica contra a mulher no Distrito Federal”. In: CNPq, UNIFEM, MEC, MCT, SPM/PR (Org.). $6^{\circ}$ Prêmio Construindo a igualdade de gênero - Redações, artigos científicos e projetos pedagógicos premiados. Brasília: Presidência da República, Secretaria de Políticas para as Mulheres, 2010. v. 1, p. 149-163.

CAMPOS, Carmen Hein de. "Razão e sensibilidade: teoria feminista do direito e Lei Maria da Penha". In: ___ (Org.). Lei Maria da Penha comentada em uma perspectiva jurídicofeminista. Rio de Janeiro: Lumen Juris, 2011. p. 1-12.

CAMPOS, Carmen Hein de; CARVALHO, Salo de. "Tensões atuais entre a criminologia feminista e a criminologia crítica: a experiência brasileira". In: CAMPOS, Carmen Hein de (Org.). Lei

\footnotetext{
${ }^{41}$ Previsto pelo Código Civil Brasileiro: "Art. 146 - Constranger alguém, mediante violência ou grave ameaça ou depois de lhe haver reduzido, por qualquer outro meio, a capacidade de resistência, a não fazer o que a lei permite, ou a fazer o que ela não manda. Pena: detenção, de três meses a um ano, ou multa" (BRASIL, 2002).

${ }^{42}$ Registro 01. Entrevista com promotor de justiça da promotoria especializada, em 31 de janeiro de 2011.
}

574 Estudos Feministas, Florianópolis, 23(2): 561-576, maio-agosto/2015 
Maria da Penha: comentada em uma perspectiva jurídico-feminista. Rio de Janeiro: Lumen Juris, 2011. p. 143-169.

CLADEM - Comité de América Latina y el Caribe para la Defensa de los Derechos de la Mujer. Los lentes de género en la justicia internacional. Tendencias de La jurisprudencia del Sistema Interamericano de Derechos Humanos relacionada a los derechos de las mujeres. Lima: Cladem, 2011.

COUTURIER, Mathias. "Les évolutions du droit français face aux violences conjugales: De la préservation de l'institution familiale à la protection des membres de la famille". Dialogue, n. 191, 201 1/1. Disponível em: http://www.cairn.info/revue-dialogue-2011-1-page-67.htm. Acesso em: 3 abr. 2012.

DE LAURETIS, Teresa. "A tecnologia do gênero". In: HOLLANDA, Heloisa Buarque de (Org.). Tendências e impasses: o feminismo como crítica da cultura. Rio de Janeiro: Rocco, 1994.

DEBERT, Guita Grin; GREGORI, Maria Filomena; PISCITELLI, Adriana (Org.). Gênero e distribuição da justiça: as Delegacias de Defesa da Mulher e a construção das diferenças. Campinas: Pagu/Núcleo de Estudos de Gênero-Unicamp, 2006. v. 1.

ESTIGARA, Adriana. "O dever de adotar políticas públicas em decorrência da atuação do Sistema Interamericano de Direitos Humanos: Uma análise a partir dos casos 'Maria da Penha' e 'Damião Ximenes'”. In: PIOVESAN, Flávia; IKAWA, Daniela (Coord.). Direitos humanos - fundamentos, proteção e implementação: perspectivas e desafios contemporâneos. Curitiba: Juruá, 2007. p. 441-474.

FARGANIS, Sondra. "O feminismo e a reconstrução da ciência social". In: JAGGAR, Alison M.; BORDO, Susan R. (Org.). Gênero, corpo e conhecimento. Tradução de Britta Lemos de Freitas. Rio de Janeiro: Rosa dos Tempos, 1997. p. 224-240.

FAUSTO-STERLING, Anne. "Dualismos em duelo". Cadernos Pagu, n. 17-18, p. 9-79. 2001/02. Disponível em: http://www.scielo.br/pdf/cpa/n. 17-18/n1 7a02.pdf. Acesso em: 20 jun. 2010.

FONSECA, Claudia. "Quando tecnologia, lei e família convergem: questões de gênero e geração em conexão com testes de paternidade". Antropolítica: Revista Contemporânea de Antropologia, n. 26, p. 19-36, 1. sem. 2009.

FREUD, Sigmund. Obras completas: publicações pré-psicanalíticas e esboços inéditos. Rio de Janeiro: Imago, 2003. (Coleção Obras Psicológicas Completas de Sigmund Freud, v. 1).

GOMES, Anderson Soares. "Narrando fatos: História e historicidade em 'O homem do castelo alto' de Philip K. Dick”. 2004. Disponível em: www.filologia.org.br/viiicnlf/anais/caderno0708.html. Acesso em: 16 fev. 2009.

GROSSI, Miriam Pillar. "Identidade de gênero e sexualidade". Antropologia em Primeira Mão. Florianópolis: PPGAS/UFSC, 1998.

HARDING, Sandra. "Del problema de la mujer en la ciencia al problema de la ciencia en el feminismo”. In: CIENCIA Y FEMINISMO. Madrid: Ediciones Morata, enero, 1996. cap. I, p. $15-27$.

HIRIGOYEN, Marie-France. A violência no casal: da coação psicológica à agressão física. Tradução de Maria Helena Kühner. Rio de Janeiro: Bertrand Brasil, 2006.

IBGE - Instituto Brasileiro de Geografia e Estatística. Atlas do Censo Demográfico 2010. Disponível em: http://censo2010.ibge.gov.br/apps/atlas/. Acesso em: 12 fev. 2012.

LEVERT, Isabelle. Les violences surnoises dans le couple: les identifier, les comprendre, s'en débarrasser. Paris: Robert Laffont, 2011.

MILLER, Mary Susan. Feridas invisíveis: abuso não-físico contra mulheres. Tradução de Denise Maria Bolanho. São Paulo: Summus, 1999. 
MONTMINY, Lyse. Older Women's Experiences of Psychological Violence in their Marital Relationships. Montréal, 2005. Disponível em: http://www.haworthpress.com/web/JGSW. Acesso em: 20 fev. 2012.

NORA, Pierre. "Entre memória e história: a problemática dos lugares". Tradução de Yara Aun Khoury. Projeto História. Revista do Programa de Estudos Pós-Graduados em História, PUCSP, n. 10, p. 7-28, dez. 1993.

OAB/PR. "Violência de gênero do Estado do Paraná" Relatório apresentado durante audiência pública da Comissão Parlamentar Mista de Inquérito 'Violência contra a Mulher no Brasil'”. 25 jun. 2012. Disponível em: http://www.senado.gov.br/comissoes/ documentos/SSCEPI/TextosVCM.pdf. Acesso em: 5 ago. 2012.

OPS - Organización Panamericana de la Salud. Modelo de leyes y políticas sobre violencia intrafamiliar contra las mujeres. Washington, 2004. Disponível em: http://new.paho.org/ hq/index.php?option=com_content\&task=view\&id=91\&ltemid=220. Acesso em: 10 ago. 2011.

PIMENTEL, Adelma. Violência psicológica nas relações conjugais. São Paulo: Summus, 2011. RIFIOTIS, Theóphilos. "Violência policial e imprensa: o caso da Favela Naval". Revista São Paulo em Perspectiva, v. 13, n. 4, p. 28-41, 1999.

"Derechos humanos y otros derechos: aporias sobre procesos de judicialización e institucionalización de movimentos sociales". In: ISLA, Alejandro (Org.). En los márgenes de la ley. Inseguridad y violencia en el cono sur. Buenos Aires, Barcelona, México: Paidós, 2007. p. 238.

SCOTT, Joan. "Gênero: uma categoria útil de análise histórica". Educação \& Realidade, Porto Alegre, v. 16, n. 2, p. 71-79, , jul./dez. 1990.

SILVA, Luciane Lemos da; COELHO, Elza Berger Salema; CAPONI, Sandra Noemi Cucurullo de. "Violência silenciosa: violência psicológica como condição da violência física doméstica". Interface - Comunic, Saúde, Educ, v. 11, n. 21, p. 93-103, jan./abr. 2007. Disponível em: http://www.scielo.br/pdf/icse/v1 1n21/v1 1n21 a09.pdf. Acesso em: 15 nov. 2008.

[Recebido em 27 de janeiro de 2014 e aceito para publicação em 5 de fevereiro de 2015]

\begin{abstract}
From Body's Pain to Soul's Pain: The Maria da Penha Law's Psychological Violence's Concept

Abstract: This article aims to show the results of field research conducted between December 2010 and July 2011 in a city in southern Brazil, about the exploitation of the concept of psychological violence, brought by Maria da Penha Law ( Law 11.340/06), in order to read the law using this concept. Data are primarily related to agents working at a Women Police Station, and also prosecutors. At these locations, I sought to understand how the concept of psychological violence is worked by agents and its theoretical and practical meaning. Anyway, this concept is used to question the implementation of the law, to think the changes that are occurring in the condition of women in situations of violence and to problematize the relationship between local and global in the studied field position. The methodology consisted of ethnographic and bibliographic research in the fields of Law, Psychology and Anthropology.

Key Words: Psychological Violence; Law 11.340/06; Agents of Security and Justice.
\end{abstract}

576 Estudos Feministas, Florianópolis, 23(2): 561-576, maio-agosto/2015 